\title{
Adherence to ocular hypotensive therapy: patient health education needs and views on group education
}

This article was published in the following Dove Press journal:

Patient Preference and Adherence

17 January 2013

Number of times this article has been viewed

\author{
Heather Waterman' \\ Lisa Brunton' \\ Cecilia Fenerty ${ }^{2}$ \\ Jane Mottershead ${ }^{2}$ \\ Cliff Richardson' \\ Fiona Spencer ${ }^{2}$ \\ 'School of Nursing, Midwifery \\ and Social Work, University \\ of Manchester, Manchester, UK; \\ 2Manchester Royal Eye Hospital, \\ Manchester, UK
}

Correspondence: Heather Waterman Room 6/3I4a, Jean McFarlane Building, School of Nursing, Midwifery and Social Work, University of Manchester, Manchester MI3 9PT, UK

Tel +44 I6I 306786 I

Email heather.waterman@manchester.ac.uk
Background: In this study the authors sought both to understand the health education needs of patients with glaucoma, with particular regard to adherence to glaucoma treatment, and to examine these patients' views of group education.

Methods: Using a health promotion approach to health education, 27 qualitative interviews with new and established patients receiving glaucoma treatment were conducted. Health promotion is defined as a way of strengthening people's capacities to control and optimize their own health. The interviews were transcribed and were then analyzed thematically.

Results: Nine categories of health education needs were identified from the transcripts: (1) to understand glaucoma; (2) to understand their diagnosis or understand the difficulties in giving a diagnosis; (3) to understand the implications of eye drops, their side effects, and how to renew the eye drops; (4) to feel confident to put in eye drops; (5) to put the condition into perspective - to know how to manage their risk; (6) to be able to ask questions of clinicians; (7) to be able to navigate the health care system; (8) to understand and be able to manage own adherence behavior; and (9) to know where to access other sources of information. The majority of patients had something positive to say about group education, and about half of the patients said they would attend group education if they were offered the opportunity.

Conclusion: A health promotion approach identified a wide range of patient-centered health education needs regarding adherence to glaucoma treatment. Group education will be attractive to some patients. Clinicians could use the health education needs identified in this study to guide the development of either individual or group-based educational intervention to improve adherence to glaucoma treatment. However, clinicians need to be aware that when developing a group intervention, attention will need to be given to making the education relevant to the circumstances of each patient.

Keywords: glaucoma, patient compliance, treatment compliance, therapy adherence, action research

\section{Introduction}

Glaucoma is the leading cause of permanent blindness and partial sightedness worldwide, ${ }^{1,2}$ with the estimated 60.5 million people living with glaucoma in 2010 increasing to 76.2 million by 2020 as the global population grows older. ${ }^{2}$ As in other long-term conditions, there is a tendency in patients with glaucoma not to follow prescriptions as prescribed. ${ }^{3,4}$ Olthoff et al's ${ }^{4}$ evidence-based review found that between $5 \%$ and $80 \%$ of patients did not adhere to their prescribed medication; the range of proportions of patients who did not adhere arose from the different definitions of and methods utilized for measuring adherence. The extent to which patients with glaucoma continue to take eye drops as prescribed without discontinuation has also been shown to be poor. ${ }^{5-7}$ For the purpose of this article, adherence 
is defined as the degree to which medication-taking behavior "corresponds with agreed recommendations from a health care provider." 3 Poor adherence to therapy is considered to be a contributory factor in the progression of glaucoma. ${ }^{8}$

There is a great deal of research that has investigated factors that affect whether patients instill eye drops as prescribed. Four reviews of the literature report that the cause of nonadherence to glaucoma medication is multifactorial. ${ }^{4,-11}$ However, while this research is useful, it is not set in the context of identifying health education needs as a precursor to developing an educational intervention to improve adherence.

Educational interventions to improve adherence can be delivered to single patients, groups of patients, or a mixture of both. A systematic review found group education to have an impact equivalent to individual education on patient glycemic control in type 2 diabetes, ${ }^{12}$ and another review (also of type 2 diabetes) reported there was evidence to indicate that group education increases self-empowerment, quality of life, and satisfaction with treatment. ${ }^{13}$ The present authors could find only two studies that clearly indicate an intervention was group-based education for patients with glaucoma, but neither of these studies report that the interventions are based on empirical research on patients' health education needs and both were unclear about the impact on patient outcomes including adherence. ${ }^{14,15}$ There is also a dearth of research on how patients view group education. In other education studies that aim to improve adherence to glaucoma treatment, it is not reported as to whether interventions are based on an analysis of the health education needs of patients. ${ }^{16-18}$ Therefore, further research is required to investigate patients' health education needs regarding adherence to glaucoma treatment and to examine patients' views on group education as preliminary work to developing a group intervention.

In this article, the authors present findings originating from an action research project that was a collaboration between patients, health professionals, and university researchers and which sought to develop a group-based education program to improve adherence to glaucoma eye drops. Action research is defined as a participatory and cyclical process that aims to advance knowledge while executing an improvement in health care practices. The work presented here was the first stage of that project and aims to understand the health education needs of patients with glaucoma, with particular regard to adherence to glaucoma treatment, and to examine these patients' views of group education.

\section{Methods}

Qualitative research methods were selected to enable an in-depth exploration of patients' health education needs regarding the promotion of adherence to glaucoma treatment and these patients' views on group education. One of the strengths of this approach is that through open-ended questioning, participants' understanding can be elicited. For the purpose of this study, health education is defined as "any planned activity designed to produce health- or illnessrelated learning." 19 The authors took a health promotion approach to health education - health promotion is defined as a way of strengthening and optimizing people's capacities to control their own health. ${ }^{20}$ Proponents of this approach argue that when people are empowered through patient-led learning, they are more likely to take action to enhance their health. ${ }^{19}$ Patient-led learning is defined as learning that is determined by the patient as opposed to being decided by the health care professional. Arguably, patient-led learning is likely to make the content of an education program more relevant to the needs of patients. This study received research ethics approval (reference number: 09/H1008/4) from NRES Committee North West-Greater Manchester Central, Manchester, UK, and all participants gave informed consent prior to participation in the study.

\section{Sample and methods of data collection}

The method of sampling was purposive. The authors set broad inclusion criteria: (1) outpatients, (2) $\geq 18$ years of age, (3) diagnosed with chronic open-angle glaucoma or ocular hypertension or normal-tension glaucoma, (4) newly diagnosed and established patients, thus giving access to experiences along the continuum of patients that would be useful to know in the development of an educational intervention, and (5) prescribed hypotensive eye drops. Exclusion criteria were (1) angle-closure glaucoma, diabetic retinopathy, or allergies to ocular medication, and (2) unavailability of interpreter.

The authors collected data from patients at outpatient clinics in a regional ophthalmology hospital in the North-West of the UK. Initially, a cross-section of people were approached to take part - this cross-section included patients of different ages, sex, ethnicities (defined as white, black, or other), socioeconomic backgrounds (defined by employment), and stages of disease progression (defined as new or established patients) - in order to grasp a range of perspectives. The authors did not set out to predetermine the number of patients in each of these categories. To fix the sample size "a priori" 
would serve to restrict the ability to respond to the data according to what is found. This would be counterproductive to one of the strengths of qualitative research - specifically, its flexibility and adaptiveness. As the authors progressed, the emerging patterns of data determined who should be interviewed. Patient recruitment for interviews stopped when data saturation occurred - that is, when no new information on the themes was forthcoming. ${ }^{21}$

The aim of the interviews was to identify the health education needs of patients in terms of adherence to eye drops. Patients were given a choice to be interviewed either at home or in the clinic. Drawing on a health promotion approach, ${ }^{20}$ open-ended questions were asked about the following:

- the type of information that would be useful for patients to know about glaucoma and how this relates to adherence;

- the patient's attitudes to eye drops (ie, whether he or she thought eye drops were effective) and whether he or she personally needed and instilled eye drops;

- whether the patient had been taught how to instill eye drops and how the patient evaluated his or her competence in instilling eye drops;

- the type of support that the patient needed in order to understand his or her condition and to help him or her to instill eye drops.

The interviewer was allowed to ask questions in an unscripted manner in order to follow up comments made by patients. This is one of the strengths of qualitative research, because it means that the findings are as reflective of the patients' agenda as they are of the researchers'. Patients were also asked about their views on group education and whether they would attend such an event. A research assistant who was a trained nurse and who was not involved in the clinical care of patients carried out all the interviews.

\section{Rigor}

Several strategies during the research were employed to ensure rigor, a couple of which have already been discussed: a flexible approach to sampling and the concurrent collection and analysis of data. Another approach was member checking. ${ }^{22}$ Member checking is defined as gaining research participant feedback on the accuracy of the researcher's interpretation. By relating back or summarizing the meaning and content of what the participants had said at the time of the interview, member checking was achieved. Rigor was also demonstrated by feeding back patient interview transcripts to the management group - this group was made up of professional and patient representatives who oversaw the project for their insight into elicited themes.

\section{Data analysis}

The digitally recorded data from the patient interviews were transcribed verbatim and loaded onto NVivo (v 8; QSR International Pty Ltd, Melbourne, Victoria, Australia), a qualitative data analysis program that assists with nonnumerical data indexing, searching, and organizing. ${ }^{22}$ Data analysis was performed concurrently with data collection, thus also allowing for an iterative and responsive approach. The transcripts were read and reread by the university researchers in order to encourage familiarity with content and to gain an overview of emerging patterns in the data. The data of each transcript were inspected for any indication of health education needs and views on group education. These were coded line by line, and similar codes were grouped into themes. The themes constituted nine health education needs and an additional theme on group education.

\section{Results}

Twenty-seven participants were interviewed (Figure 1). There were slightly more women than men interviewed (52\% and $48 \%$, respectively). Forty-four percent of participants were in the 60-69 age bracket, and most were retired $(63 \%)$ and newly diagnosed within the previous 12 months (63\%). Eighty-nine percent of the participants were white, with only two black participants (7\%), and one classed as "other" ethnicity (4\%) (Table 1). The interviews lasted between 30 minutes and 1 hour. Those who refused to be interviewed cited not wanting to be bothered or

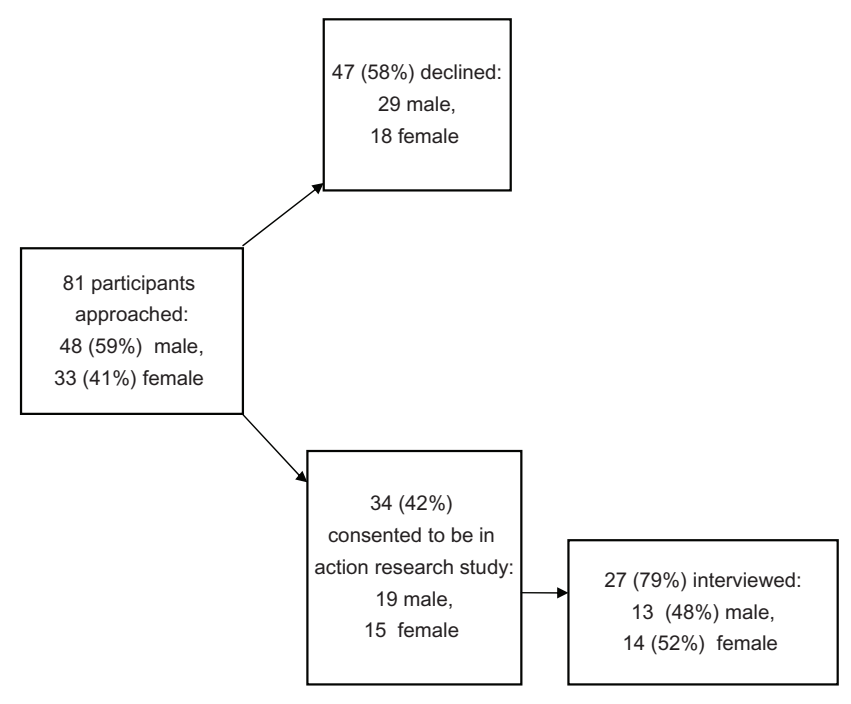

Figure I The study's recruitment and selection process. 
Table I Demographic characteristics of interviewed participants $(\mathrm{N}=27)$

\begin{tabular}{ll}
\hline Characteristic & Participants [n (\%)] \\
\hline Sex & $13(48 \%)$ \\
Male & $14(52 \%)$ \\
Female & \\
Age (years) & $3(11 \%)$ \\
Under 50 & $4(15 \%)$ \\
$50-59$ & $12(44 \%)$ \\
$60-69$ & $5(19 \%)$ \\
70 and over & $3(11 \%)$ \\
Missing & \\
Employment & $5(19 \%)$ \\
Full-time & $1(4 \%)$ \\
Part-time & $1(4 \%)$ \\
Unemployed & $17(63 \%)$ \\
Retired & $2(7 \%)$ \\
Unable to work because of ill-health & $1(3 \%)$ \\
Missing & \\
Ethnicity & $24(89 \%)$ \\
White & $2(7 \%)$ \\
Black & $1(4 \%)$ \\
Other & \\
Time since diagnosis & $17(63 \%)$ \\
New $(<12$ months) & $10(37 \%)$ \\
Established $(\geq 12$ months) &
\end{tabular}

being too busy for their nonparticipation. The results are first organized as per the nine health education needs identified:

1. to understand glaucoma;

2. to understand their diagnosis or understand the difficulties in giving a diagnosis;

3. to understand the implications of eye drops, their side effects, and how to renew the eye drops;

4. to feel confident to put in eye drops;

5. to put the condition into perspective - to know how to manage their risk;

6. to be able to ask questions of clinicians;

7. to be able to navigate the health care system;

8. to understand and be able to manage own adherence behavior;

9. to know where to access other sources of information.

The tenth theme identified discusses patients' responses to group education. To avoid the criticism of anecdotalism, illustrative quotes and examples of the full range of viewpoints are provided. Direct quotes will be found in the text - the patient interview number is given after each quote.

\section{To understand glaucoma}

Patients felt that they ought to be told about glaucoma and how it was treated so that they could take action to help themselves. While some of the patients interviewed knew glaucoma was "high eye pressure," others had completely wrong explanations for glaucoma pathology and risk factors. Patients described not being aware of the dangers of glaucoma and what it did to them, and patients complained they were told simply that they had glaucoma and received little else in the way of information. A few patients argued that had they known what glaucoma did to their vision, they could have taken preventive action against progression. As one patient reported:

You know, they don't explain, but if they [patients] know it's to reduce the pressure in your eye to stop them going

blind I think they might remember. [Patient 01]

Therefore, the data demonstrate there was a need in the sample to be informed about glaucoma because it helps patients to make sense of their condition and, thus, to understand the implications of their condition if it were left untreated. In other words, being informed provides patients with a justification for instilling their eye drops.

\section{To understand their diagnosis or understand the difficulties in giving a diagnosis}

Furthermore, while most patients knew their diagnosis, there was a small group of patients who did not understand why it had taken, or was taking, a long time to make a diagnosis. As one patient describes:

Nobody actually said to me "you've definitely got glaucoma", they just kept saying you've got ... the pressures are increased in your eyes. It was only over time I was getting letters back, copies of letters that were sent to my GP [general practitioner] that did say I had glaucoma on it. [Patient 04]

Additionally, a few patients reported they had been given conflicting information about their diagnosis when seen by different clinicians and that they had found this confusing. Therefore, patients need to have their diagnosis explained or they need to be provided with reasons as to why this is not yet possible.

\section{To understand the implications of eye drops, their side effects, and how to renew the eye drops}

Patients also appeared to know little about their eye drops and the side effects of treatment. A common pattern that emerged from the data was that some patients had been unaware of the side effects of eye drops (a red eye that 
lasts for about 3 weeks) and as a consequence had mistakenly stopped putting them in. A few patients did not tell their doctor about stopping the eye drops and continued to nonadhere for months. Some patients felt strongly that had they received education regarding the eye drops, they would have understood the consequences of nonadherence. For example, one patient explained:

I just said the drug was no good ... I wasn't using it, but if I had enough information, I would be using that drug, even if my eyes are reddish. [Patient 13]

Personal motivating reasons for adherence focused on their beliefs about the efficacy and outcomes of instilling eye drops. One woman expressed concern about the toxicity of eye drops. She was skeptical about all medicines and this led directly to her nonadherence, as she stated:

I was reluctant to take, I'm ... I'm ... I seem to sort of, um, don't do very well with drugs, I always feel queasy and, or, you know, if I take antibiotics and things like that. And I didn't want to take statins 'cause I know they ... and I have an idea that these pills, these drops that they put in your eyes, they're ... sort of antihypertensive ones aren't they, they bring your blood pressure down which kind of thing, err, I maybe ... . I don't know, err, I'm a bit suspicious of them [laughs] ... So, err, I ... I mean obviously they've got to do their business and they've obviously got to be toxic ... . But, err, yeah, I ... I just don't do these pills and medicines. [Patient 07]

Apart from her beliefs, her understanding of the purpose of eye drops was confused and incorrect. In contrast, patients who claimed to be adherent could not understand why other patients would risk losing their eyesight by not putting in their drops. In other words, these patients were motivated by having positive beliefs and also thought the outcome of instilling eye drops would be positive, whereas Patient 07 had negative beliefs in the efficacy of drops and also evaluated the outcomes negatively. These beliefs appeared to be linked to how much the patients knew about glaucoma and its treatment. However, it should be noted that some patients were adherent without having this knowledge.

Lack of knowledge of side effects was frequently associated with having no or inaccurate information about both the daily timing of eye drops and how and when to renew eye drops; altogether, this could result in an impediment to adherence as observed among some patients. Therefore, it appears that an education program would need to include information about the implications of eye drops, their side effects, and how to renew the eye drops.

\section{To know where to access other sources of data}

In order to overcome this lack of information, some patients had sought information from the Internet. These patients generally stated they found the information useful, as typified by this comment:

I found it [the Internet] useful for the fact that I knew what glaucoma was ... but unfortunately the doctors are very busy, so they said "oh well, you've got glaucoma and we're gonna treat it, gonna give you drops, keep it under control and I'll see you in three months". And before you know where you are you're out, and you think "What do you mean? What does he mean?" [Patient 11]

Only one patient reported accessing the website of the International Glaucoma Association. This demonstrated a need in the sample for further reliable information on glaucoma to be accessible outside of the hospital eye clinic.

\section{To put the condition into perspective - to know how to manage their risk}

Furthermore, a few patients appeared to be either excessively anxious about their condition or blasé about its consequences, as demonstrated in the following quotes:

Um it's just a word to me. Do you know what I am saying? ... It doesn't really mean a lot to me. You know, I'm not worried about the word or the disease you know - as long as I can see ... I think that's my only concern. [Patient 09]

This book I've got, well I didn't buy it because of glaucoma and it's a good thing I didn't ... I went through this medical book and started crying because this woman had glaucoma and her eyes looked like two fried eggs in the picture ... and so there's a lot of scary bits about it, you know? [Patient 10]

These personal assessments of the severity of their condition, coupled with other issues discussed earlier in this article, left some patients vulnerable to over- or underprecaution in terms of their eye drops, which reinforced their adherence behavior. This finding suggests patients need to understand the medical plan of care so that, for example, they can understand their target pressure and how they can contribute to achieving it, where possible. 


\section{To be able to ask questions of clinicians}

The interview data reveal that some patients were passive in their relationships with health care professionals, were unable to explain their needs, and received little support from professionals. For example, a patient discussed his lack of understanding of medical terminology that in turn prevented him from asking more questions:

He [doctor] said "we'll keep an eye on it, your pressure's 17" which didn't particularly mean anything to me at the time. The unfortunate thing is, if you're with somebody ... and they tell you something, and it's something you haven't got a clue about the subject, and what you tend to is not know what to ask, you've no sensible questions. [Patient 11]

In contrast, some patients reported how they were confident in asking questions and were able to build a rapport with health care professionals, explain what their needs were, and gain the information they needed to successfully manage their condition. There appears a need to help patients know what questions to ask and to help them feel confident in asking these questions.

\section{To be able to navigate the health care system}

Another related issue was that patients commonly reported concern at the postponement of routine follow-up clinic appointments. Referrals from optometrists to hospital eye services have increased in the United Kingdom since the introduction of the National Institute for Health and Clinical Excellence ${ }^{24}$ guidelines. ${ }^{25}$ However, many patients were reluctant, or baffled about how to, complain and therefore did not do anything about their concern regarding postponement of routine follow-up clinic appointments. Those patients who did try to address their concern reported contradictions in how different parts of the health care system perceived the severity of their condition. One man reported how he felt concerned when a secretary at a specialist hospital told him he did not need an early appointment whereas his local consultant told him he did. This served to discourage or demotivate some of the patients with regard to treatment adherence. Having the knowledge and skills to challenge or navigate the health care system to achieve their goals seemed important to some of the patients interviewed.

\section{To feel confident to put in eye drops}

In the study sample, patients reported objective difficulties in both instilling eye drops and remembering to put them in. Additionally, in some instances, patients reported they initially did not or still did not have the confidence to perform these tasks. One patient stated:

I mean it becomes like cleaning your teeth in the end I'm quite sure. But it's just developing that skill and it just would have been quite nice to have somebody, you know, going, don't worry it will come right. [Patient 07]

While some patients mastered the skill of instilling eye drops relatively easily, others expressed concern that they were not taught how to instill eye drops at the hospital. A patient told how he had convinced himself for the first 2 months that forgetting the eye drops was alright; he put this down to not feeling confident immediately to put in eye drops and not understanding the implications of the condition. For those patients who could not instill their eye drops, carers were often employed to instill the drops; however, this dependence left patients vulnerable to nonadherence when carers were unavailable.

Many patients forgot to instill the eye drops for various reasons. The patients frequently expressed an inability to incorporate this new behavior into their routine, explaining that they had not yet adapted their routines and lifestyle away from home to include the instillation of eye drops. For example, one patient stated:

Oh aye, I've forgot already, yeah ... just the odd night. You

know, it just depends what I've been doing or if I've been out or something like that. I come in and I've been a bit tired and I've just put me head down and realised the next morning I didn't put them in. [Patient 16]

Arguably, patients need to be taught to be proficient in (or need someone to assist with) putting in eye drops and also need to be supported with remembering to put the eye drops in and incorporating the eye drops into their lives.

\section{To understand and be able to manage own adherence behavior}

In the study sample, while some patients had managed to work out for themselves how to incorporate eye drop instillation into their routine and were in a position to maintain positive behavior, the quotes in the previous section show how some patients were or had been nonadherent. The reported ongoing difficulties and length of time taken to resolve the patients' difficulties, if these difficulties were resolved at all, suggests that patients need assistance in identifying and implementing adherence behavior. 


\section{Patient views on group education}

The majority of patients had something positive to say about group education because they saw it as a place to share ideas and have a discussion with other patients. One patient argued:

Well I think if you're in a group then people will come up with questions which you might not have come up with. And that would be one advantage I suppose. [Patient 17]

Others identified that group education would be good for people who lacked confidence or who were at home alone:

It has advantages for people who are, em, lack confidence and, em, well are frightened ... if they're on their own with nobody to do anything for them. [Patient 14]

Others thought that they would be able to see how they themselves coped with glaucoma compared with others, as one patient described:

Err - it would be nice to hear about other people and how they cope ... You know, like see who is worse off than me, how do they cope on a daily basis. [Patient 09]

While many patients could identify advantages to group education, about half said they would not actually attend group education, suggesting that "it was not for them," that they felt it would not be useful, or they would not be able to attend because of work.

\section{Discussion}

By taking a health promotion approach to health education, the authors have identified several health education needs from the patients' perspective. ${ }^{19}$ There appears to be a range of needs, including to understand the diagnosis, condition, treatment, and treatment side effects; to be motivated to instill eye drops; to have the confidence and skills to instill eye drops; to perceive and have the ability to perform a range of adherence behavioral skills to be adherent; to have the confidence to ask questions of health care professionals; and to be able to challenge or navigate the health care system. Therefore, the focus of the health education needs identified in this study is not only on imparting knowledge but also on providing and helping patients feel confident in technical and communication skills sufficient for them to feel empowered to contribute meaningfully to their care.

As an approach to delivering patient health education, group-based education appeared to be acceptable to patients. The authors see group-based education as one of many approaches to health education - other complementary approaches include delivery of education to single patients. It would depend on a patient's needs as to whether delivery of education in a group or individually would be the most suitable approach. Further research is required to investigate whether patients will actually be recruited and attend groupbased education. A randomized controlled trial could usefully investigate whether group and single delivery have at least equivalent patient outcomes in terms of adherence.

The establishment of several health education needs regarding adherence for patients on glaucoma treatment will enable the development of an intervention to promote adherence in this group of patients. Other research has found there is a need to tackle multiple causes of nonadherence. For example, Schwartz et $\mathrm{al}^{26}$ found that the number of adherence problems was significantly correlated to nonadherence to eye drops. Similarly, Sleath et $\mathrm{al}^{27}$ found that the number of reported difficulties with instilling eye drops was significantly associated with reporting less than $100 \%$ adherence in the previous week. Multifaceted interventions have also been shown to be effective in general adherence research. ${ }^{28}$

The findings of the present study support those of other studies that have attempted to identify links between doctorpatient communication and adherence to glaucoma treatment. For example, in the Glaucoma Adherence and Persistency Study it was reported that $34 \%$ of questions asked by patients in consultation with their glaucoma physician were about intraocular pressure and disease status, and a further $20 \%$ focused on the medication regimen. ${ }^{29}$ These patient issues are similar to some of the health education needs identified by the present study. Another finding from the Glaucoma Adherence and Persistency Study demonstrates that, generally, physicians dominate consultations while patients are passive and are reluctant to ask questions. ${ }^{29,30}$ Again, this is similar to the present study's finding that some patients report difficulty in asking about their condition. Other North American studies have also identified poor communication between doctor and patient as a contributory factor in poor adherence. . $^{31,32}$

The present study is the first time, to the best of the authors' knowledge, that the issue of adherence to glaucoma eye drops has been framed in a health education context. The authors found that not knowing one's diagnosis or the reasons for the difficulties with giving a diagnosis are a contributory factor to poor adherence. This issue with adherence could either be a reflection of the difficulties in giving a diagnosis or because of poor recall on behalf of patients, or the problem could lie with the practitioners having poor communication skills, which could be compounded by the "busy-ness" of 
clinics in the United Kingdom. Therefore, the findings of this study suggest that an assessment of patients' knowledge of diagnosis needs to be incorporated into an intervention to help patients to place their experience in context and to take appropriate action.

\section{Limitations of the study}

Selection bias from the qualitative methodology, the single site for recruitment from a regional eye hospital, and the small sample size are limitations of this study. A larger, multicenter sample may have produced more definitive findings but data saturation occurred at the single site, which gives credence to the findings. The findings also present a rich cross-section of patients' experiences that would be difficult to obtain from quantitative research. Arguably, social desirability bias did not appear to be a huge factor in the responses of the interviewees, given the range of reported experiences. The authors conclude that a nonjudgmental approach with open-ended questions allowed patients to respond without undue influence. However, the interviews may have led to introspection that may have, in turn, led to discussion of needs that may or may not exist or impact on adherence. Therefore, further research is needed to investigate whether it is necessary to deliver all the health education needs identified to achieve adherence.

This study was carried out in the United Kingdom, where it could be said there is a tendency for a paternalistic approach to health care, which may deny patients information while at the same time making patients reluctant to ask questions. ${ }^{33}$ Given this bidirectional bias, it would appear necessary for researchers developing adherence interventions to first investigate the health needs of their population of patients, as these needs could differ from country to country depending on the pervading professional culture of care.

Other studies have found organizational and provider factors could also influence patients' adherence rates. ${ }^{31,34}$ The World Health Organization ${ }^{35}$ also states that health promotion should tackle structural determinants of health including poor literacy. Therefore, the onus should not always be on the patient to change but, rather, should be shared among patients, the health care system, and health care professionals.

\section{Conclusion}

To the best of the authors' knowledge, this is the first time that the issue of adherence to glaucoma eye drops has been framed in a health education context. The research found that patients expressed a range of different types of health education needs that appear to be interrelated and which need to be addressed in an educational intervention. Some of the findings are reminiscent of those found in the literature that has considered the risk factors or causes of nonadherence. The qualitative approach taken in this study offers an in-depth insight into the behavior and experiences of patients. The findings suggest that group education will be appealing and appropriate for some but not all patients. Altogether, the findings of this study suggest that group delivery needs to be cognizant of patients' individual circumstances so that the patients are able to apply the knowledge and skills acquired through the education to their own situation. Group-based education also needs to be tested to observe whether it is at least as equivalent in effecting patient outcomes as education delivered to single patients.

\section{Acknowledgments}

The authors are extremely grateful to the staff and patients who so kindly gave their time to participate in this study. The authors are also indebted to the Burdett Trust for Nursing, who funded this research. Thanks also go to the staff at Central Manchester NHS Trust and Manchester Royal Eye Hospital who hosted and facilitated the study.

\section{Disclosure}

The authors report no conflicts of interest in this work.

\section{References}

1. Resnikoff S, Pascolini D, Etya'ale D, et al. Global data on visual impairment in the year 2002. Bull World Health Organ. 2004;82(11): 844-851.

2. Quigley HA, Broman AT. The number of people with glaucoma worldwide in 2010 and 2020. Br J Ophthalmol. 2006;90(3): 262-267.

3. World Health Organization (WHO). Adherence to Long-Term Therapies: Evidence for Action. Geneva: WHO; 2003.

4. OlthoffCM, Schouten JS, van de Borne BW, Webers CA. Noncompliance with ocular hypotensive treatment in patients with glaucoma or ocular hypertension: an evidence-based review. Ophthalmology. 2005;112(6):953-961.

5. Schwartz GF, Platt R, Reardon G, Mychaskiw MA. Accounting for restart rates in evaluating persistence with ocular hypotensives. Ophthalmology. 2007;114(4):648-652.

6. Ajit RR, Fenerty CH, Henson DB. Patterns and rate of adherence to glaucoma therapy using an electronic dosing aid. Eye (Lond). 2010;24(8):1338-1343.

7. Reardon G, Kotak S, Schwartz GF. Objective assessment of compliance and persistence among patients treated for glaucoma and ocular hypertension: a systematic review. Patient Prefer Adherence. 2011;5: 441-463.

8. American Academy of Ophthalmology (AAO). Primary open-angle glaucoma summary benchmarks. San Francisco, CA: AAO; 2012. Available from: http://one.aao.org/CE/PracticeGuidelines/SummaryBenchmark. aspx?cid=13a96c9d-2605-42bd-8eed-bd6b770fdae0.Accessed November 22, 2012.

9. Schwartz GF. Compliance and persistency in glaucoma follow-up treatment. Curr Opin Ophthalmol. 2005;16(2):114-121. 
10. Tsai JC. Medication adherence in glaucoma: approaches for optimizing patient compliance. Curr Opin Ophthalmol. 2006;17(2):190-195.

11. Schwartz GF, Quigley HA. Adherence and persistence with glaucoma therapy. Surv Ophthalmol. 2008;53(Suppl 1):S57-S68.

12. Deakin TA, McShane CE, Cade JE, Williams RD. Group based training for self-management strategies in people with type 2 diabetes mellitus. Cochrane Database Syst Rev. 2005;2:CD003417.

13. Duke SA, Colagiuri S, Colagiuri R. Individual patient education for people with type 2 diabetes mellitus. Cochrane Database Syst Rev. 2009;1:CD005268.

14. Blondeau P, Esper P, Mazerolle E. An information session for glaucoma patients. Can J Ophthalmol. 2007;42(6):816-820.

15. Kim S, Stewart JF, Emond MJ, Reynolds AC, Leen MM, Mills RP. The effect of a brief education program on glaucoma patients. J Glaucoma. 1997;6(3):146-151.

16. Gray TA, Orton LC, Henson D, Harper R, Waterman H. Interventions for improving adherence to ocular hypotensive therapy. Cochrane Database Syst Rev. 2009;2:CD006132.

17. Okeke CO, Quigley HA, Jampel HD, et al. Interventions improve poor adherence with once daily glaucoma medications in electronically monitored patients. Ophthalmology. 2009;116(12): 2286-2293.

18. Gray TA, Fenerty C, Harper R, et al. Individualised patient care as an adjunct to standard care for promoting adherence to ocular hypotensive therapy: an exploratory randomised controlled trial. Eye (Lond). 2012;26(3):407-417.

19. Green J, Tones K. Health Promotion: Planning and Strategies, 2nd ed. London: Sage; 2010

20. Naidoo J, Wills J. Developing Practice for Public Health and Health Promotion, 3rd ed. London: Bailliere Tindall; 2010.

21. Pope C, Mays N. Qualitative Research in Health Care. Malden, MA: Wiley-Blackwell; 2006.

22. QSR International. NVivo 8. Melbourne: QSR International; 2011. Available from: http://www.qsrinternational.com/products_previousproducts_nvivo8.aspx.

23. Waterman H, Annis G. IGA open summer patient meeting. IGA News. Winter 2011:15-25.

24. National Institute for Health and Clinical Excellence (NICE). Glaucoma: Diagnosis and Management of Chronic Open Angle Glaucoma and Ocular Hypertension; NICE Guideline 85. London: NICE; 2009.
25. International Glaucoma Association (IGA). NICE Quality Standards for glaucoma: the end of the queue for patients? [press release]. Ashford, UK: IGA; 2011 [March 30]. Available from: http://www.glaucomaassociation.com/media.html. Accessed December 9, 2011.

26. Schwartz GF, Plake KS, Mychaskiw MA. An assessment of readiness for behaviour change in patients prescribed ocular hypotensive therapy. Eye (Lond). 2009;23(8):1668-1674.

27. Sleath B, Ballinger R, Covert D, Robin AL, Byrd JE, Tudor G. Self-reported prevalence and factors associated with nonadherence with glaucoma medications in veteran outpatients. Am J Geriatr Pharmacother. 2009;7(2):67-73.

28. Haynes RB, Ackloo E, Sahota N, et al. Interventions for enhancing medication adherence. Cochrane Database Syst Rev. 2008;2:CD000011.

29. Friedman DS, Hahn SR, Quigley HA, et al. Doctor-patient communication in glaucoma care: analysis of videotaped encounters in community-based office practice. Ophthalmology. 2009;116(12): 2277-2285.

30. Friedman DS, Hahn SR, Gelb L, et al. Doctor-patient communication, health-related beliefs, and adherence in glaucoma: results from the Glaucoma Adherence and Persistency Study. Ophthalmology. 2008;115(8):1320-1327.

31. Taylor SA, Galbraith SM, Mills RP. Causes of non-compliance with drug regimens in glaucoma patients: a qualitative study. $J$ Ocul Pharmacol Ther. 2002;18(5):401-409.

32. Tsai JC, McClure CA, Ramos SE, Schlundt DG, Pichert JW. Compliance barriers in glaucoma: a systematic classification. J Glaucoma. 2003; 12(5):393-398.

33. Stevenson FA, Cox K, Britten N, Dundar Y. A systematic review of the research on communication between patients and health care professionals about medicines: the consequences for concordance. Health Expect. 2004;7(3):235-245.

34. Vandenbroeck S. Keeping an Eye on Glaucoma Patients: Patient Reported Outcomes, Adherence to Eye Drop Treatment and Eye Drop Administrative Skills [doctoral thesis]. Leuven: Catholic University of Leuven; 2011.

35. WHO Milestones in Health Promotion Statements from Global Conferences (2009) http://www.who.int/healthpromotion/Milestones_ Health_Promotion_05022010.pdf. Accessed December 9, 2012.
Patient Preference and Adherence

\section{Publish your work in this journal}

Patient Preference and Adherence is an international, peer-reviewed, open access journal focusing on the growing importance of patient preference and adherence throughout the therapeutic continuum. Patient satisfaction, acceptability, quality of life, compliance, persistence and their role in developing new therapeutic modalities and compounds to

\section{Dovepress}

optimize clinical outcomes for existing disease states are major areas of interest. This journal has been accepted for indexing on PubMed Central. The manuscript management system is completely online and includes a very quick and fair peer-review system. Visit http://www.dovepress.com/ testimonials.php to read real quotes from published authors. 